\title{
Electrical conductivity features of the Arctic shelf permafrost and electromagnetic technologies for their studies
}

\author{
E. A. Piskunova ${ }^{1}$, N. A. Palshin ${ }^{1}$, and D. V. Yakovlev ${ }^{2}$ \\ Received 15 May 2018; accepted 2 July 2018; published 6 September 2018.
}

The change in the ice conditions in the Arctic made it possible to study vast areas of the shelf by geophysical methods, including electromagnetic ones. The structure of the Arctic shelf subsea permafrost differs from the well-studied continental permafrost due to its accelerating degradation caused by the action of near-bottom waters. The features of the subsea permafrost are reflected in the electrical conductivity of rocks, since this property is sensitive to parameters such as the pore fluid salinity and pore ice/gas hydrate content. The capabilities and resolution of various marine electromagnetic technologies are analyzed, especially in application to the Arctic shelf exploration, an area with the sea depths of up to $100 \mathrm{~m}$, where relict permafrost may exist. KEYWORDS: Arctic Ocean coastal shelves; permafrost; electrical conductivity; marine geophysics; electromagnetic methods.

Citation: Piskunova, E. A., N. A. Palshin, and D. V. Yakovlev (2018), Electrical conductivity features of the Arctic shelf permafrost and electromagnetic technologies for their studies, Russ. J. Earth. Sci., 18, ES5001, doi:10.2205/2018ES000628.

\section{Introduction}

Studies of the Arctic shelf permafrost are one of the most complex and urgent challenges faced by marine geophysics. The term permafrost is defined as the upper part of the Earth's crust, where temperature remains lower than $0^{\circ} \mathrm{C}$ for a sufficiently long period of time (from $2-3$ years to millennia and more) and where ice-bonded permafrost can exist. Permafrost may contain ice (and/or gas hydrate) in one form or another, as well as thawed rocks [Osterkamp, 2001; Yakupov, 2008]. Permafrost is widely distributed on the Earth and is well studied onshore in the coastal regions of the Arctic, but the structure of the permafrost and ice-

\footnotetext{
${ }^{1}$ Shirshov Institute of Oceanolgy RAS, Moscow, Russia

${ }^{2}$ Nord-West Ltd, Moscow, Russia
}

Copyright 2018 by the Geophysical Center RAS. http://rjes.wdcb.ru/doi/2018ES000628-res.html bonded permafrost distribution in the Arctic seas remains poorly known. Potentially, regions where the ice-bonded permafrost could have been formed and exist for a long time, include areas of the continental Arctic shelf with sea depths less than 100 $120 \mathrm{~m}$ [Brothers et al., 2016, Romanovskii et al., 2005. It is believed that ice-bonded permafrost is widely spread across the shallow shelf of all Arctic seas: Barents, Kara, Beaufort and especially the Laptev Sea, the East Siberian and Chukchi Seas [Lindgren et al., 2016, Malakhova, 2014, Osterkamp, 2001, Rachold et al., 2007.

Ice-bonded permafrost is an impermeable caprock (aquifuge and gas proof), below which free gas, primarily methane, can accumulate. The upper boundary of the gas hydrates stability zone lays below or within the permafrost, therefore significant amount of both gas hydrate and gaseous methane can accumulate in this region [Andreassen et al., 2017. Portnov et al., 2016. The flooding of vast areas following the last glaciation led to a sharp change in temperature and caused gradual 
thawing of the ice-bonded permafrost in the shelf zone and, as a consequence, to numerous seafloor methane emissions, as observed in the Arctic seas [Menzies and Van der Meer, 2018]. Those processes are also insufficiently studied. For example, questions relating to the origin of methane and the amount of its release are still widely debated [e.g. Shakhova et al., 2010, 2017]. Data characterizing the shelf permafrost structure make a significant contribution to the solution of a number of both fundamental and applied problems.

Integrated studies of permafrost are extremely important for understanding the processes of permafrost degradation and associated methane emissions, as well as for risk assessment and optimal solution selection for submarine pipeline laying and oil drilling platform construction. Practical problems relevant to the development of the Arctic shelf that are to be solved, include: (1) mapping the ice-bonded permafrost distribution area, (2) studying the structure of the whole permafrost and icebonded permafrost in particular, (3) estimating the total thickness of the ice-bonded permafrost, and (4) investigating the geological structure of the subpermafrost sediments, including the tectonic faults and/or gas and gas hydrates accumulations mapping. Shelf permafrost studies include geological sampling (with seabed soil samplers, or corers) and drilling for the complex investigations of seabed sediments, as well as geophysical studies. Geophysical methods are an efficient tool for the shelf permafrost studies that include high-resolution seismic exploration, electromagnetic (EM) prospecting and high-precision gradient magnetic surveys. EM methods provide information on the electrical conductivity structure of the oceanic lithosphere. The main objective of this research is to study the features of the electrical conductivity of permafrost rocks on the shelf, including features associated with cryogenic and post-cryogenic processes, as well as an assessment of the capabilities and prospects available with electromagnetic methods in application to the shelf permafrost studies.

\section{Permafrost and Ice-Bonded Permafrost on the Arctic Shelf}

All the Arctic territories experienced a warming that began 19,000 years ago, as well as a sea level rise, especially rapid in the last 15,000 years. As a result, most of the permafrost on the present Arctic shelf to depths of about 100-120 m was formed in the subaerial conditions of tundra and flooded in the last 3000 years, as a consequence of which the upper part of the sedimentary cover may contain relict permafrost [Brothers et al., 2016, Romanovskii et al., 2005. Besides, the newly formed permafrost can be distinguished, which is formed within the sea depth range from $40-50$ to $250 \mathrm{~m}$ with a temperature of -1.5 to $-1.8^{\circ} \mathrm{C}$ and has thickness of up to 80-100 m [Shpolyanskaya, 2015]. Figure 1 shows the bathymetry map of the Laptev and East Siberian seas. It is believed that over $80 \%$ of the all offshore permafrost of the Northern Hemisphere is located on the East Siberian shelf [Shakhova et al., 2017]. It can be seen that in these two seas, vast areas may contain submarine icebonded permafrost (since sea depth doesn't exceed $100 \mathrm{~m}$ ). These are huge offshore areas, where the study of the permafrost and ice-bonded permafrost distribution and structure, as well as of the underlying sedimentary formations, becomes an actual task. It should be noted that twenty years ago this was practically impossible, since most of the Arctic seas were covered with ice throughout the year (see Figure 1). In contrast, for example, in September 2017, the boundary of the ice cover was moved significantly to the north and its location approximately coincided with the $100 \mathrm{~m}$ isobath, which made it possible to conduct geological and geophysical surveys for subsea permafrost exploration using research vessels.

Figure 2 shows a schematic section of permafrost. It can be seen that onshore ice-bonded permafrost exists in the region from the Earth's surface to depths of about $500 \mathrm{~m}$. On land, the zone of gas hydrate stability is located slightly below the icebonded permafrost or may intersect with it; while offshore it is located closer to the seafloor and can reach the seafloor at greater sea depths. Obviously, this is only a model, while actual location of ice- bonded permafrost and the gas hydrates stability zone depends on the type of sediments, the temperature of the bottom water and a temperature gradient. The structure of the ice-bonded permafrost layer is complicated by various heterogeneities: taliks (including through taliks), thawed zones beneath river beds and bays, etc. The origin of taliks and other structures can be associated 

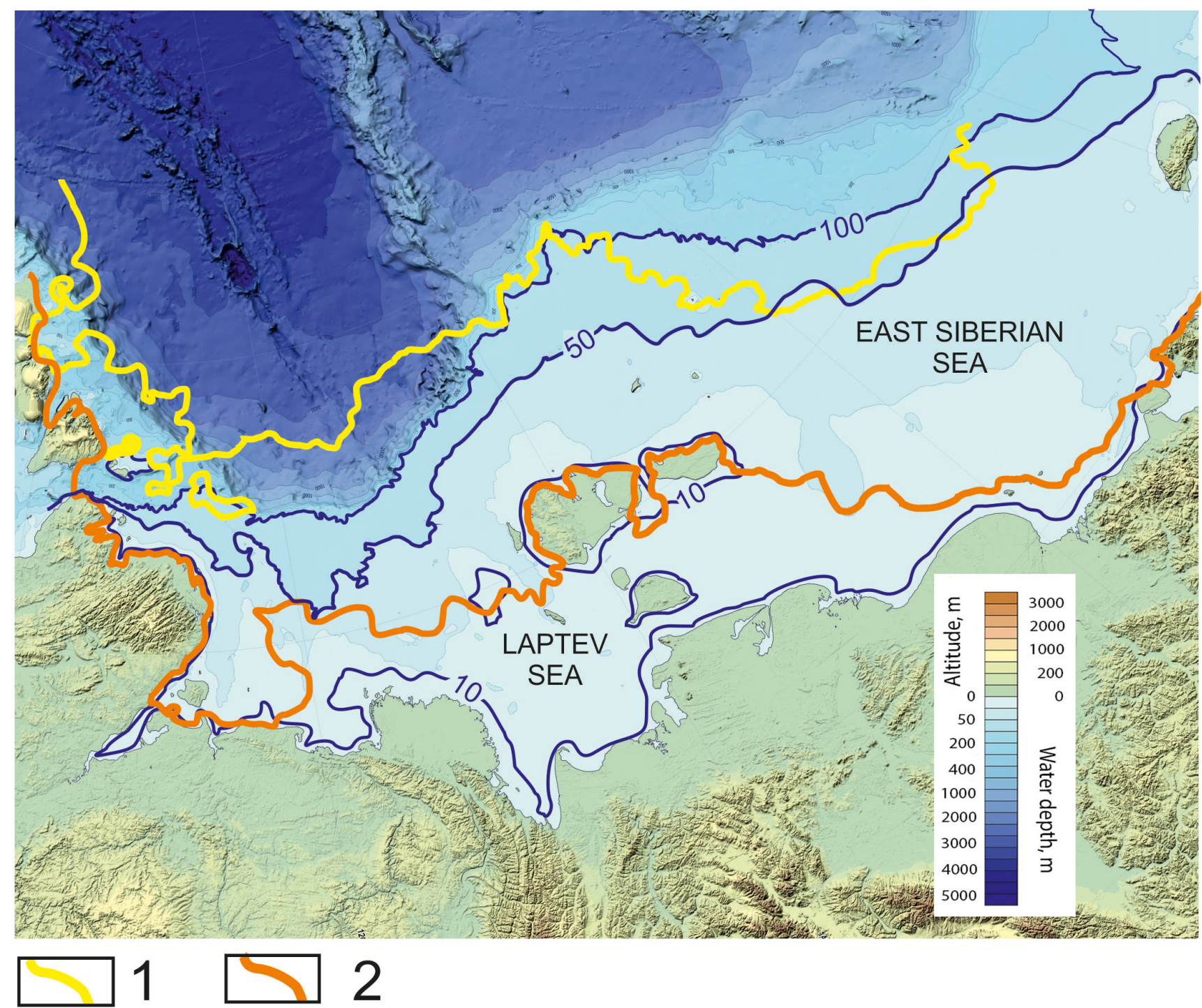

Figure 1. Bathymetric chart of the Laptev and East-Siberian seas. Bold isobath lines correspond to 10, 50 and $100 \mathrm{~m}$ depth. Explanation: 1 - ice cover boundary in September 2017, 2 - ice cover boundary in September 1998.

with both cryogenic lakes and those formed as a result of gas explosions [Andreassen et al., 2017, Leibman et al., 2017.

After the land submersion, these structures appear to be partially preserved in the form of pockmarks, pingos and craters [Paull et al., 2007]. According to the data of geophysical studies, gas flares of different intensity are associated with these features, which are a visible evidence of the degradation of the subsea permafrost [Kiselev and Reshetnikov, 2013, Lobkovskiy et al., 2015, Shakhova et al., 2010, 2017.

When transgression occurs, the above structures can cause accelerated and spatially inhomogeneous degradation of the subsea permafrost with manifestations in the form of methane emission zones, if they reach the gas front [Frederick and Buffett, 2014. An additional, post-cryogenic mechanism affecting subsea permafrost is a plough of floating ice hummock, resulting in deep grooves ("plough marks"), which can have a depth of $4-6 \mathrm{~m}$ and a length of up to several $\mathrm{km}$. The plough marks are found across nearly all the shelf and play the role of methane release sites [Lobkovskiy et al., 2015 Montelli et al., 2018. Woodworth-Lynas et al., 1991. Thus, the structure of the offshore per- 

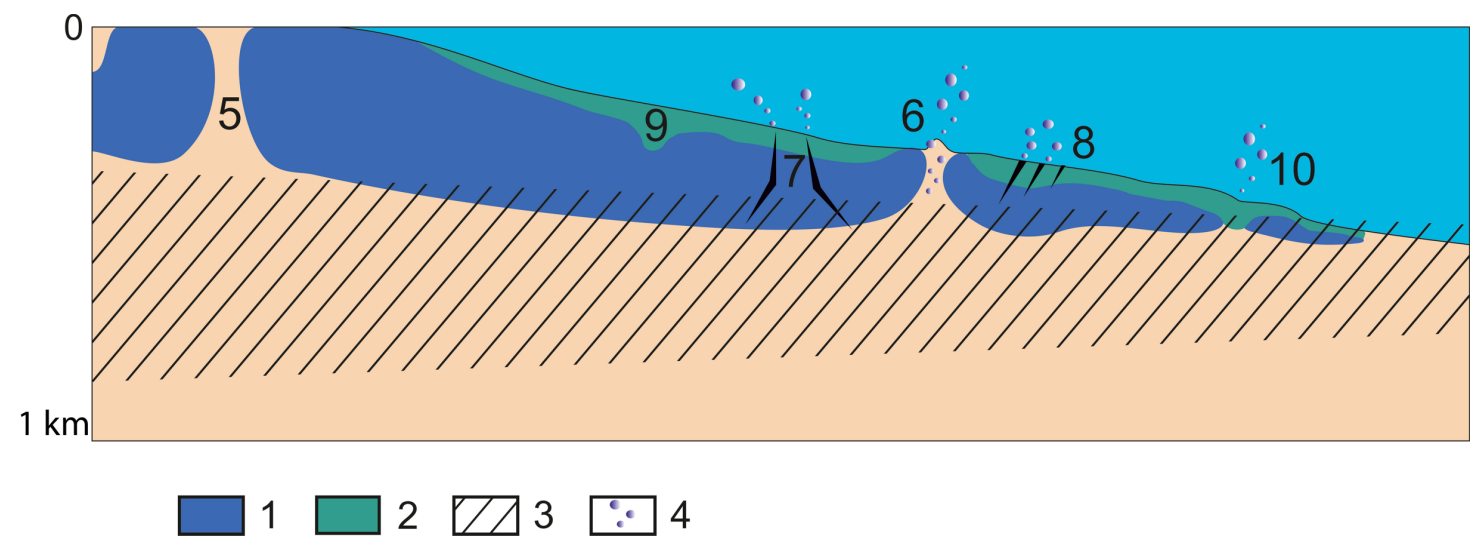

Figure 2. Schematic section of the onshore (left) and subsea (right) permafrost. Explanation: 1 - ice-bonded permafrost, 2 - near-bottom thawed layer, 3 - gas hydrate stability zone, 4 - methane release site, 5 - through talik, 6 - pingo, 7 - cracks, 8 - plough marks, 9 - paleobed, 10 - crater.

mafrost is defined by both cryogenic (freezing of the upper formations during sea regressions) and postcryogenic (permafrost degradation during transgressions) processes.

Thawing of the shelf relict ice-bonded permafrost is caused by the increased temperature of the bottom waters compared to that of the arctic air (bottom waters' temperature is usually slightly negative and varies from -0.5 to $-1.5^{\circ} \mathrm{C}$ ). In turn, thawing of the relict permafrost, which is a gas proof and aquifuge layer, leads to the emission of methane from the relict permafrost and, possibly, from the sub permafrost gas hydrate accumulations [Frederick and Buffett, 2014, Menzies and Van der Meer, 2018. In recent years, the processes of the subsea Permafrost degradation have apparently accelerated due to the climate change in the Arctic [Lobkovskiy et al., 2015, Portnov et al., 2013, 2016, Rekant et al., 2015.

The main difference between the offshore and onshore permafrost is the presence of an uppermost thawed layer and a higher degree of degradation due to the bottom waters impact. Similar to the onshore settings, the offshore gas hydrate stability zone can have intersection with the permafrost.

The subsea permafrost may contain ice and/or gas hydrate both in the massive form and as a cement in sedimentary rock, while some other parts of the rock may remain thaw if pore solutions' mineralization is sufficiently high. It is important to note that the presence of the fluid with high salinity in the pores of the rock causes the freezing point to be substantially lower than $0^{\circ} \mathrm{C}$, that is, unfrozen ("thawed") layers can exist even at negative temperatures.

Features of the subsea permafrost structure are also related to the numerous cycles (decrease/increase) of the ocean level, which form the layered structure of the upper sedimentary formations. During the transgression cycles, relatively loose marine sediments were deposited, while intense freezing of the initial surface during regressions led to the formation of dense dehydrated rocks [Lobkovskiy et al., 2015. Osterkamp, 2001.

The main evidence shedding light on the permafrost distribution was obtained as a result of geotechnical drilling in coastal regions with sea depth of 5-10 m. There aren't much factual data available on the state and thickness of the subsea permafrost on the shelf where sea depths exceed $20 \mathrm{~m}$.

To study the ice-bonded permafrost distribution and the processes of permafrost degradation, numerical modeling is widely used, which has pointed out an important role of the bottom waters' temperature as well as salinization of the seafloor sediments (latter defines the seasonal thaw depth), for the current state of the subsea permafrost. Estimates of the rate of vertical degradation of subsea permafrost scatter significantly, and the radiocarbon dating of methane gives a complex pattern of its origin [Malakhova, 2014, Shakhova et al., 2010. 2017. To a large extent, this is due to the insufficient amount of experimental data and specific features of the geological structure of seabed sediments. 


\section{Electrical Conductivity of Permafrost}

Electrical exploration, or electromagnetic method (EM), is one of the most efficient geophysical technologies for permafrost studies [Baranov et al., 2014: Yakovlev et al., 2017; Yakupov, 2008. The main outcome of the EM exploration is the image representing a two- or three-dimensional model the electrical conductivity distribution in the subsurface (in practical EM projects, the reciprocal of electrical conductivity, called electrical resistivity, is more often used). The interpretation of EM data is based on understanding of the mechanisms that determine the electrical conductivity of rocks. At this point it should be mentioned that most of the rocks entirely forming the subsea permafrost on the Arctic shelf, are sedimentary rocks.

Sedimentary rocks are a multiphase medium. To a first approximation, we can assume that the sedimentary rock consists of a non-conducting matrix and a conducting fluid (aqueous solution of various salts). Charge carriers in solutions (fluids) are positive and negative ions, formed from the molecules of salts, acids, and alkalis when those are being dissolved by water (solvent). Since the electrical conductivity of the matrix is negligible, the conductivity of a sedimentary rock depends on fluid's conductivity and its volume, with latter being defined by the coefficient of effective porosity.

Thus, the resistivity of the sedimentary rock mainly depends on only two quantities - the electrical conductivity of the fluid and the rock porosity, which is reflected by the well-known empirical relations proposed by Archie and Dakhnov [Archie, 1942. Dakhnov, 1941. For the clay rocks containing a significant number of particles with an effective diameter of less than 10 micrometers, the above relations are barely applicable, since the electrical conductivity of such rocks weakly depends on the salinity (conductivity) of the fluid. This is due to the fact that the pores in clay rocks have subcapillary dimensions, which results in arising of the socalled "surface" conductivity mechanism. In addition, the electrical conductivity obviously depends on the temperature. Thus, the electrical conductivity of sedimentary rocks depends on: (1) clay content, (2) effective porosity, (3) fluid saturation, (4) electrical conductivity of pore fluid. Along with the composition of dissolved ions and temperature, an important factor determining the electrical con-
Table 1. Dependence of the electrical conductivity of the brackish and saline water on temperature and salinity (according to the equations from [Weyl, 1964])

\begin{tabular}{ccc}
\hline Salinity, g/l & \multicolumn{2}{c}{ Electrical resistivity, $\Omega \mathrm{m}$} \\
\hline & $0^{\circ} \mathrm{C}$ & $5^{\circ} \mathrm{C}$ \\
\hline 1.00 & 8.333 & 7.143 \\
2.00 & 4.505 & 4.000 \\
5.00 & 2.000 & 1.724 \\
10.00 & 1.075 & 0.926 \\
20.00 & 0.575 & 0.498 \\
25.00 & 0.467 & 0.405 \\
30.00 & 0.397 & 0.345 \\
35.00 & 0.344 & 0.299 \\
40.00 & 0.306 & 0.265
\end{tabular}

ductivity of sedimentary rocks, is the pore fluid salinity. Table 1 lists the values of seawater resistivity for different salinity at $0^{\circ} \mathrm{C}$ and $5^{\circ} \mathrm{C}$ temperature.

In general, the electrical conductivity of the permafrost rocks is controlled in a complex way by the conductivity and arrangement of the rock grains/mass, ice and/or gas hydrate, gas and thawed water in the bulk [Du Frane et al., 2015. Waite et al., 2009. To a first approximation, the effective porosity (pore space initially occupied by the fluid) in ice-bearing and ice-bonded rocks decreases due to the formation of ice and/or gas hydrate, which occupy the pore space. In the beginning, ice forms thin films on the rock particles, then the ice or gas hydrate forms a skeleton inside the pores, but does not yet occupy the entire pore space, and finally completely substitutes the fluid. This process leads to a gradual decrease in the electrical conductivity of the rock, while the cooled rocks that do not contain ice and/or gas hydrate, but instead contain fluid with increased salt concentration, may exhibit, on the contrary, an increased electrical conductivity.

Figure 3 shows the results of the calculation of permafrost electrical resistivity as a function of the fluid salinity and pore ice content (neglecting the effect of surface conductivity) at $0^{\circ} \mathrm{C}$ for petrophysical parameters typical for bottom shelf sediments (see Table 1).

Estimates were obtained from the Archie's equa- 

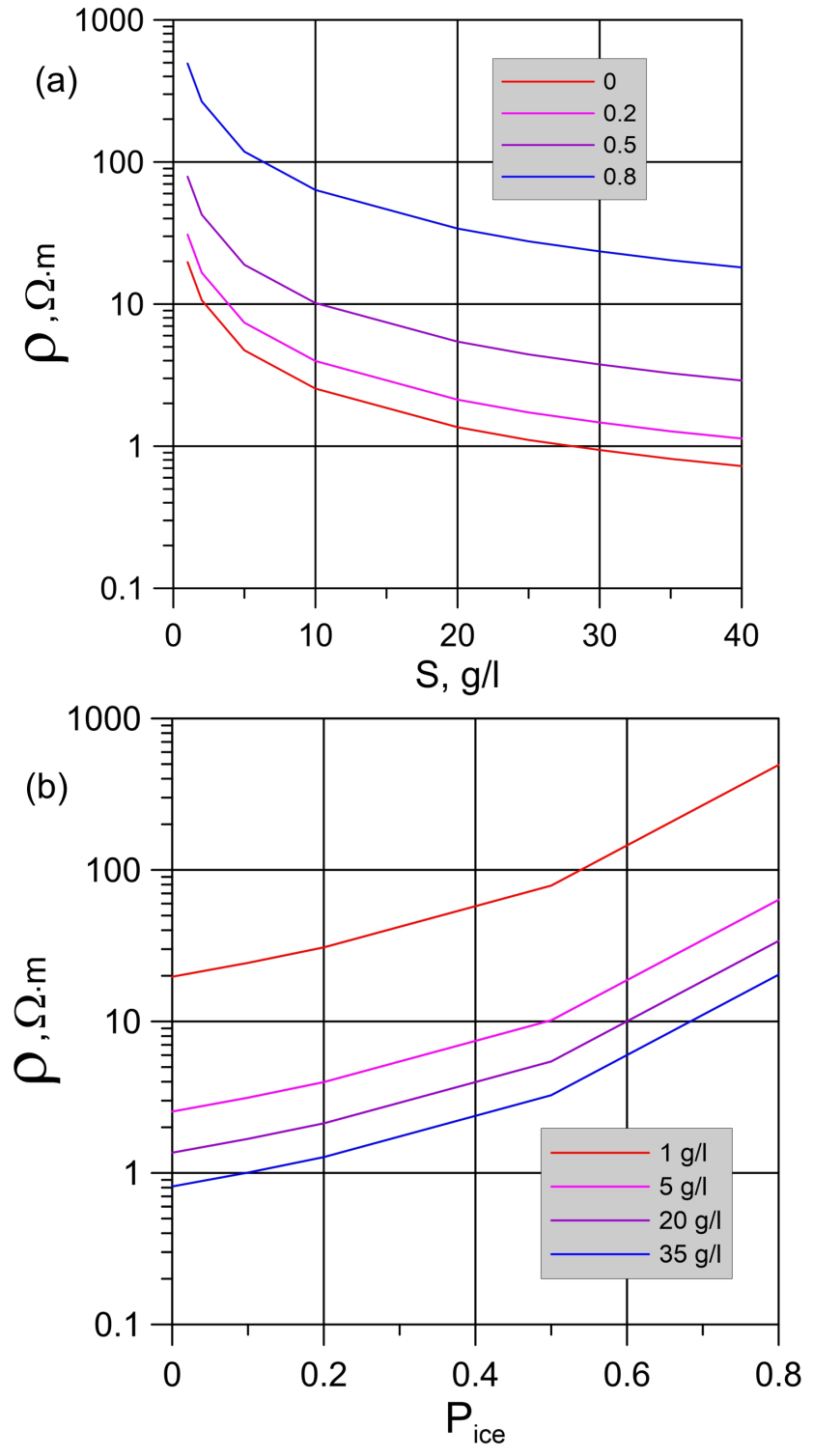

Figure 3. Dependence of the electrical resistivity $\rho$ on pore fluid salinity $S$ for different pore ice content $P_{\text {ice }}(\mathrm{a})$, and electrical resistivity versus $P_{\text {ice }}$ for different salinity values $S$ (b) assuming the effective porosity of $65 \%$ and temperature of $0^{\circ} \mathrm{C}$.

tion and the relation between fluid conductivity and salinity as indicated in Table 1, assuming that the fluid in the sea floor sediments can be partially replaced by practically non-conducting ice or gas hydrate. It can be seen that the sea bottom sediments' resistivity essentially depends on both the salinity of the fluid and the extent of rock freezing (or thawing). For fresh or brackish pore waters (with mineralization of 1 to $5 \mathrm{~g} / \mathrm{l}$ ), the rock resistivity exceeds $10 \Omega \mathrm{m}$. The presence of salt seawater in the pores reduces resistivity to about $1 \Omega \mathrm{m}$. Typi-

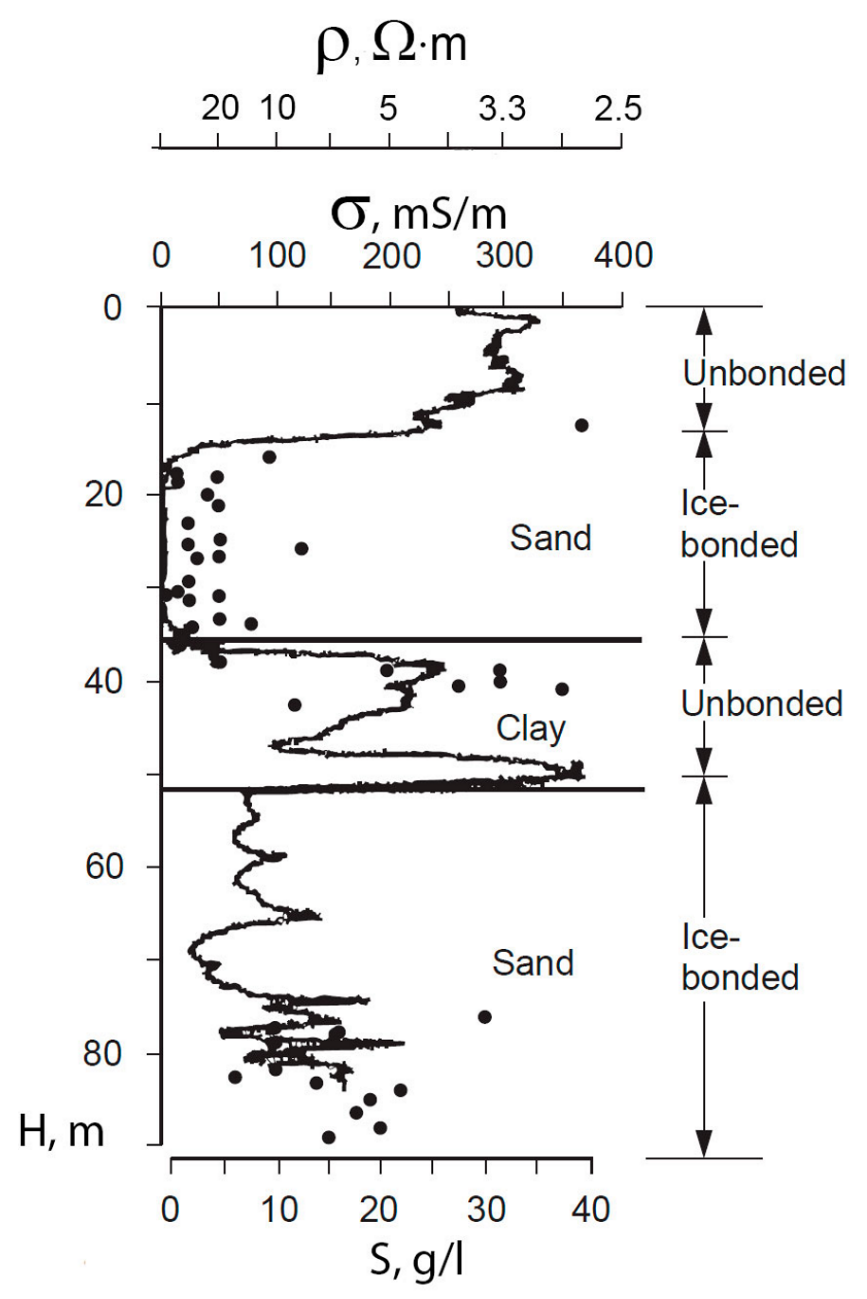

Figure 4. Dependence of the permafrost electrical conductivity $\sigma$ and resistivity $\rho$ and pore fluid salinity $S$ on depth $H$ according to the borehole logging data from the mouth of McKenzie River (Beaufort Sea) at $10 \mathrm{~m}$ sea depth. Line shows the electrical resistivity log, while the points indicate the salinity values. Modified from [Osterkamp, 2001 .

cal values of the electrical resistivity for thawed sea bottom sediments, in which the fraction of ice or gas hydrate is low, fall within the range between 1 and $3 \Omega \mathrm{m}$. In the case of rock freezing, when the fluid is replaced with ice or gas hydrate, the electrical resistivity increases, reaching several tens of $\Omega \mathrm{m}$ and more.

When constructing an electrical conductivity model of the subsea permafrost, in addition to the petrophysical and hydrophysical parameters, it is necessary to take into account both lateral and vertical (interbedding of sand and clay) inhomogeneities in its structure. 


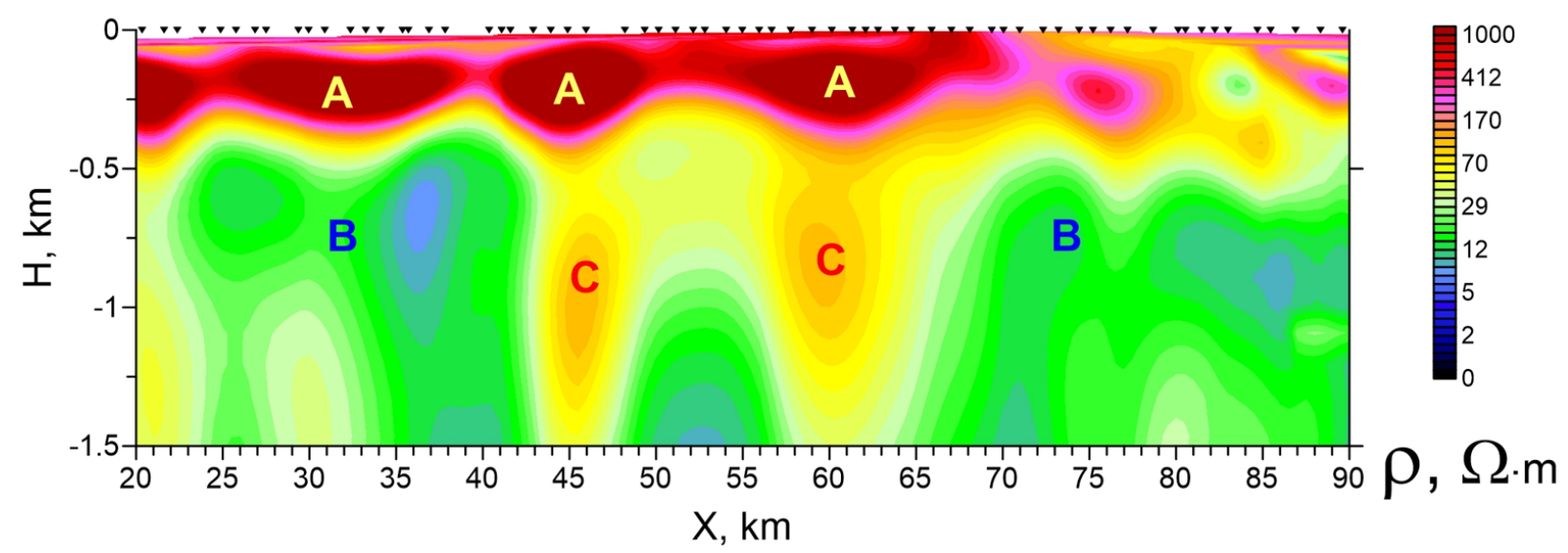

Figure 5. Resistivity image of the permafrost structure along the MT profile fragment in the Yenisei-Khatanga Trough. $X$ is the distance along profile, $H$ is depth. Electrical resistivity values are shown as a color plot, with the color scale shown in the righthand part of the figure. Black triangles indicate MT station locations. Explanation: A - ice-bonded permafrost, B - terrigenous sediments, C - gas hydrates.

Figure 4 shows the results of measurements of electrical resistivity and pore water salinity in the permafrost in the well located at the mouth of the Mackenzie River. Borehole logging data indicate the sand and clay interbedding with average layer thickness of tens of meters. Sand bands have increased resistivity (more than $10 \Omega \mathrm{m}$ ), low salinity of pore water (about $5 \mathrm{~g} / \mathrm{l}$ in the upper layer and $15 \mathrm{~g} / \mathrm{l}$ in the lower layer) and contain ice. Clay bed has low resistivity (less than $5 \Omega \mathrm{m}$ ), increased pore water salinity (20-30 g/l) and does not contain ice.

Interbedding of high- and low-resistivity layers, whose thicknesses are small compared to either electromagnetic wavelength or electroprospecting array electrode separation, for the purposes of numerical EM simulation (solving forward and inverse EM problem), can be effectively represented as an anisotropic layer in which the vertical resistivity is substantially greater than the horizontal one. Formal solution of the inverse problem without taking the macro-anisotropy into account may result in significant underestimation of the resistivity since most EM methods are more sensitive to longitudinal conductivity.

The electrical resistivity of the permafrost ranges from a few thousand of $\Omega \mathrm{m}$ for ice rocks (on land) to a few $\Omega \mathrm{m}$ for thawed rocks containing fluids with increased salinity (in sea floor sediments), which makes EM methods an effective tool for studying the structure of the permafrost zone, both on land and on the Arctic shelf.

\section{Magnetotelluric (MT) Studies of the Electrical Conductivity of Permafrost in Taymyr}

Yenisei-Khatanga Trough, a province, whose geological setting is well understood as a result of onshore magnetotelluric (MT) surveys, is a perfect natural test site for EM studies of the permafrost and its electrical conductivity features, since its section contains clearly pronounced ice-bonded permafrost formations of large thickness. Also, during the study numerous methane emissions have been observed, and it is believed that subpermafrost contains gas hydrate accumulations [Afanasenkov et al., 2015, Leibman et al., 2017. Yakovlev et al., 2018 .

As an example, we consider a typical MT survey (the data were kindly provided by Nord-West Ltd). A resistivity image for this line has been obtained as a result of two-dimensional bimodal inversion of the measured MT response data. Figure 5 shows the resistivity image to the depth of $1.5 \mathrm{~km}$ for a $70 \mathrm{~km}$-long part of the line. According to the borehole temperature logging data, the depth to the $0^{\circ} \mathrm{C}$ isotherm (permafrost lower boundary) is about $500 \mathrm{~m}$ in this region. In the upper part of the section, an ice-bonded permafrost layer is $200 \mathrm{~m}$ thick and increased resistivity of about $1000 \Omega \mathrm{m}$. The thickness of this formation varies in a wide range. 


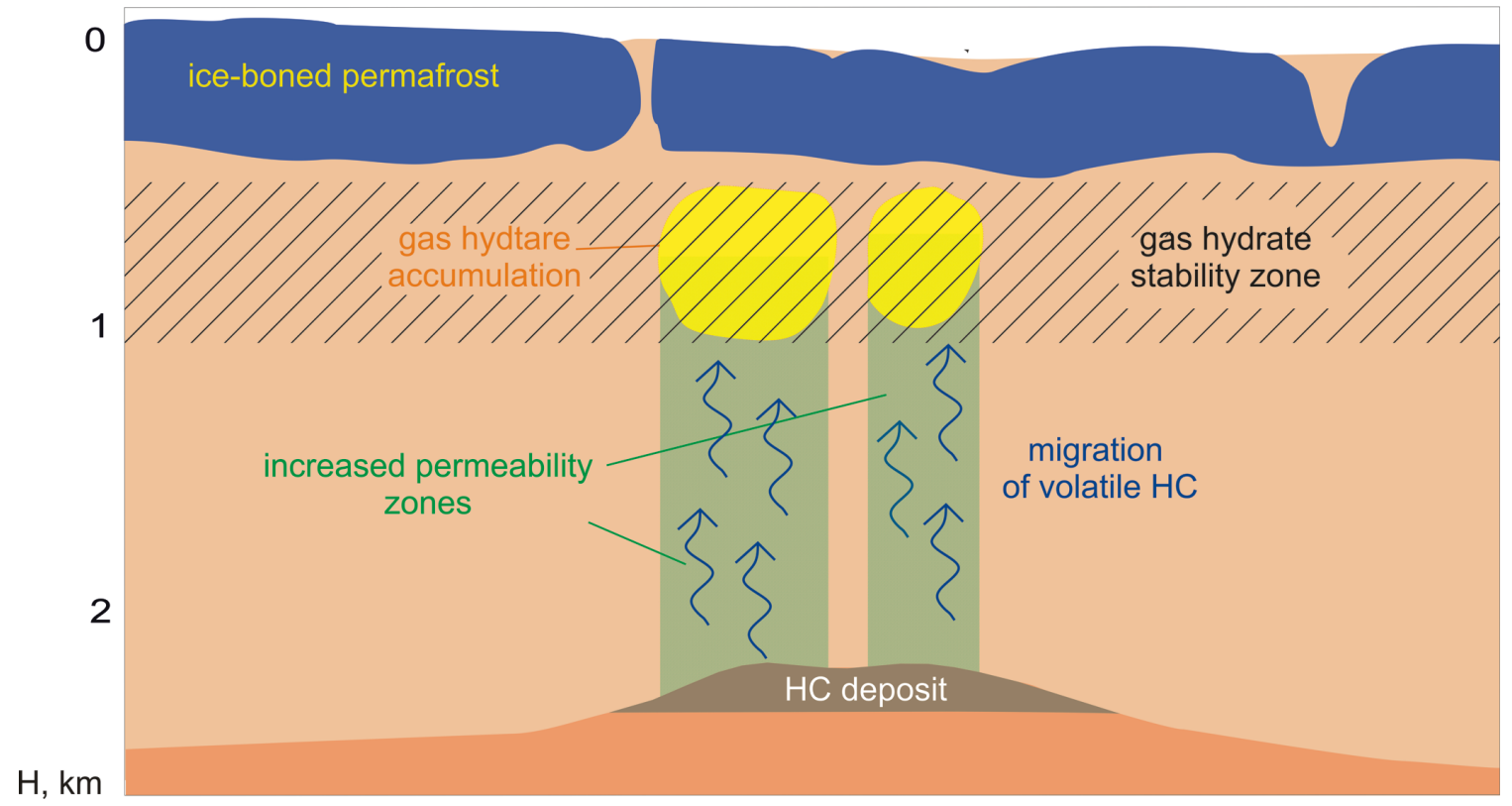

Figure 6. Hypothetical model of gas hydrate accumulation formation above the hydrocarbon (HC) deposit.

In the right-hand part of the section, the highresistivity ice-bonded permafrost is pinched-out. Below, at depths of over 300-400 m, lie terrigenous sedimentary rocks with a resistivity of less than $20 \Omega \mathrm{m}$. In the central part of the line, two regions of increased resistivity (line distance $45 \mathrm{~km}$ and 65 th $\mathrm{km}$ ) are identified. Most likely, these are associated with gas hydrates accumulations formed over a hydrocarbon deposit. Moreover, the presence of such anomalies of electrical conductivity can be considered as a new prospecting indicator, since the similar high resistivity anomalies beneath permafrost exist over several known hydrocarbon fields and cannot be explained by changes in sediment lithology [Afanasenkov et al., 2015.

A hypothetical concept of how gas hydrate accumulations are formed is illustrated by Figure 6 . To prove this concept, additional data are required, primarily geophysical and borehole geological data.

A big amount of magnetotelluric data have been collected in the Khatanga Bay area, with some of the survey lines directly crossing the bay, and measurements performed from the ice during the spring season. Based on the survey results, it became possible to image the permafrost structure directly beneath the bay and compare it with the onshore permafrost structure. The resistivity image across the Khatanga Bay is presented in Figure 7. As can be seen from the image, in its onshore part, the icebonded permafrost has a thickness of about $500 \mathrm{~m}$ and its resistivity varies between 50 and $500 \Omega \mathrm{m}$. Closer to the coastline, there are low-resistivity regions, supposedly associated with through taliks, which have resistivity of $1-20 \Omega \mathrm{m}$. In the upper part of the section, beneath the Khatanga Bay, a thawed rocks layer is identified with a thickness of about $200 \mathrm{~m}$ and resistivity of less than $10 \Omega \mathrm{m}$. The frozen rocks layer beneath the bay measures about $350-400 \mathrm{~m}$ in thickness is manifested in the image by lower resistivity $(30-100 \Omega \mathrm{m})$ compared to that in its onshore part, which is apparently due to the presence of enhanced bottom temperatures and, probably, increased salinity of pore fluids determining the existence of thawed interbeds inside this layer.

Resistivity structure of the most part of Khatanga Bay area is similar and, most likely, this pattern (with clear contrast to the onshore setting) is characteristic of the entire shelf permafrost. An important difference of the subsea permafrost from the onshore one, as is evident from the Khatanga Bay resistivity image (see Figure 7), and which is confirmed by borehole geophysical measurements in the well located in the Beaufort Sea (Figure 4, is relatively lower permafrost resistivity compared to those onshore along with the presence of thawed 


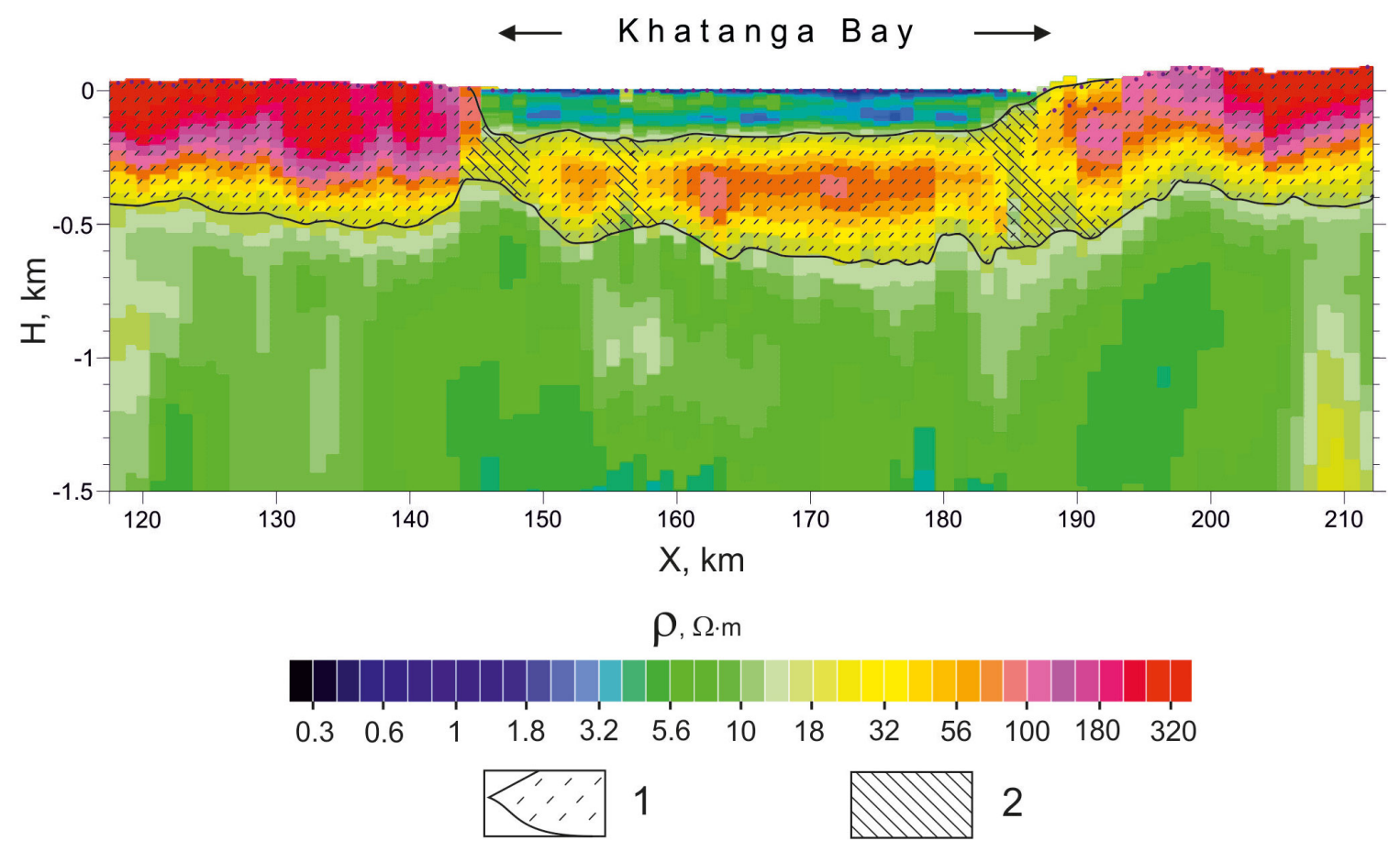

Figure 7. Resistivity image across the Khatanga Bay. $X$ is the distance along profile, $H$ is depth. Electrical resistivity values are shown as a color plot, with the color scale shown in the bottom of the figure. Explanation: 1 - ice-bonded permafrost, 2 - taliks.

formation in the upper part of the section.

In general, the magnetotelluric studies of permafrost in the Yenisei-Khatanga Trough and Khatanga Bay, where data had been recorded from ice, have shown the high efficiency of the MT method for mapping the permafrost and subpermafrost structure. The advantage of the magnetotellurics compared to the controlled-source techniques, is its significantly greater depth of investigation.

\section{EM Methods for the Sea and Ocean Floor Studies}

EM methods have a long history of a successful application in academic deep studies of the structure of the crust and upper mantle in the oceans. In the last ten to fifteen years, they have also shown efficiency in commercial geophysical exploration for hydrocarbons. Marine EM techniques differ significantly from the land modifications both in the way of EM field excitation, and in its registration. Two groups of methods are utilized offshore, as well as on land - those employing natural and controlled EM sources, each having its own advantages and shortcomings. Controlled source methods, as a rule, use a rectangular waveform electrical current of different frequency, and signal processing and data interpretation are carried out both in time and frequency domains. The advantages of the controlled source methods include higher noise immunity and the ability to map structure at small depths, however, achieved at the cost of greater technical complexity of the survey, associated with the need to excite EM field, resulting in lower economic efficiency. Whereas, the magnetotelluric sounding utilizing natural EM field, provides a large imaging depth, and is technically easier to conduct. Ideally, a combination of different methods should be applied in marine surveys [Palshin, 2009.

Controlled source surveys can be conducted with towed systems, in which array is moving at the sea surface, inside the water or being dragged along the sea floor. The most efficient technology employs measuring EM field with the help of sea floor EM stations or receiver lines are deployed at the sea floor, while the electric field is excited using a spe- 
cial source towed near the bottom [Constable, 2013 . Constable et al., 2016. This technology, which is, in fact, a combination of frequency-domain sounding and direct current (DC) resistivity profiling, found application in both academic and hydrocarbon prospecting studies [Constable, 2010, Weiss, 2007.

For the surveys aimed at mapping the uppermost layers of sea floor sediments (up to hundreds of meters in thickness) at great sea depth, for example, for studying gas hydrates accumulations in bottom sediments of the deep ocean, combined source-receiver systems are used (dipole-dipole array). Such systems provide source to receiver separation of 50 to $500 \mathrm{~m}$, with the entire array being dragged along the bottom when towing, which ensures an electrical contact of both the source and receiver dipoles directly with bottom sediments [Schwalenberg et al., 2017].

Theoretical estimates indicate that the use of a vertical electric dipole for time-domain recording of the EM field excited by a horizontal electric dipole towed at the bottom increases survey resolution at a shallow depth, which is characteristic for the shelf [Barsukov and Fainberg, 2014. One of the advantages of this technology is a lower level of noise from surface waves compared to the conventional method, in which horizontal electric field components are recorded [Flekkøy, 2012, Yegorov and Palshin, 2015, 2017]. Application of a vertical electric dipole for EM field excitation also improves the efficiency of marine methods [Barsukov and Fainberg, 2017. Helwig, 2013. Unfortunately, surveys that use vertical component of the electric field are difficult to implement.

The magnetotelluric method, being a passive technique using fluctuations of the natural EM field, is more technologically advanced, since there is no need for an EM field source. In addition, the method has great depth of investigation, which makes it possible to image a structure in a wide depth range from dozens of meters to $200-300 \mathrm{~km}$, depending on the method's modification. However, the need to measure weak natural EM field leads to a number of limitations, since the measurements can be performed only on the surface of ice or at the sea bottom, and to obtain quality data, it takes considerable time, depending on the required depth of the imaging. Normally, recording duration varies between $6-8$ hours for mapping the upper part of the crust, and several months to study the upper mantle. At a shallow depth typical for the coastal parts of the shelf, the EM field generated by surface waves is an important noise mechanism, affecting MT measurements [Yegorov and Palshin, 2015. 2017. An essential restriction of the method at a large sea depth is attenuation of high-frequency variations of the magnetic field in the water layer and, as a consequence, the inability to probe the uppermost part of the section.

The choice of a particular technology for a marine EM survey is determined by several important factors, including the depth of the sea, water salinity, target structure configuration and the required depth of investigation, as well as the distance between the survey area and the shore and the ice conditions.

The depth of the sea and water salinity determine an integral conductance of a water layer, which may exceed 20,000 $\mathrm{S}$ in the deep-water basins of the ocean (up to 40,000 S in deep-sea trenches). On the shelf, the integral conductance of the water does not exceed $1000 \mathrm{~S}$. This parameter is extremely important, since the existence of a conducting water layer on top of the section defines one of the main differences between marine and land EM methods. Thus, the most advanced technology for mapping the upper part of the crust the frequency domain - DC resistivity method with a controlled source (CSEM) is based on the attenuation of the "air" wave, and the only "useful" EM wave is the one propagating through the sea floor, which substantially increases the efficiency of this method. The depth of EM exploration for the controlled source methods is determined by the distance (offset, separation) between the source and the receiver(s) and/or the frequency of the EM signal (however, the conductivity structure itself also affects this depth) [Vanyan and Palshin, 1993. At depths less than $300 \mathrm{~m}$, the attenuation of the "air" wave (which contains no information on the sea floor structure) is weak, and its contribution to the measured signal is significant, while the resolution of the method is greatly reduced [Weiss, 2007].

Obviously, shallow depth marine EM research faces a number of challenges, especially in the transition zone. One of the effective technologies that can be applied in the depth interval from 10 to $50 \mathrm{~m}$ is the modification of bottom MT sounding developed by Nord-West Ltd. and success- 
fully tested during the surveys in the Black and Kara Seas [Epishkin, 2018, Epishkin et al., 2018]. Its specific feature is the measurement of a single component of the electric field with relatively long (50-100 m) electric dipoles. The measurements are performed by a seabed system consisting of several electric lines grounded with special-design marine electrodes, and several two-component magnetic receiver units using highly sensitive magnetic sensors (induction coils). The acquisition system, consisting of a certain number of modern-design recording units placed in pressure casings forms a sort of a streamer. It is assembled from separate parts and can have a length of more than $1000 \mathrm{~m}$. The system is deployed at the sea floor with a help of a vessel slowly moving with a certain heading; at one end of the system, an end anchor is placed, while the other end has a submerged buoy on it (see Figure 8). The length of receiver electric dipoles may vary from 50 to $100 \mathrm{~m}$, while the station spacing is from 50 to $300 \mathrm{~m}$. During the processing of acquired data, an onshore remote reference station is used for noise cancellation. The recording duration for each layout is $6-8$ hours. The period range of the observed EM field is from 0.001 to 200 $1000 \mathrm{~s}$, which corresponds to depths from 10-20 m to several $\mathrm{km}$. The use of a single component of the electric field is a limitation of this technology, but at the same time it provides higher signal-to-noise ratio (due to long electric dipoles) and increased survey productivity, which is very important due to the short duration of summer season in the Arctic.

For the EM studies on the Arctic shelf with sea depths of less than $10 \mathrm{~m}$, surface-towed dipoledipole systems, both time- and frequency-domain, can be effectively used [Sherman et al., 2017]. Besides, conventional onshore modifications of EM surveys can be applied for acquiring data from the shore ice: near-zone time-domain electromagnetics (TDEM) [Koshurnikov et al., 2016] and magnetotellurics [Yakovlev et al., 2018. As can be seen in Figure 1, areas with depth of less than $10 \mathrm{~m}$ form an insignificant part of the Laptev Sea and East Siberian Sea.

At depth of 10 to $50 \mathrm{~m}$, the bottom MT modification developed by Nord-West is efficient. It is important to note that the MT sounding method is capable of probing deep formations, namely obtaining information on the structure of the entire sedimentary cover and even the crystalline base-

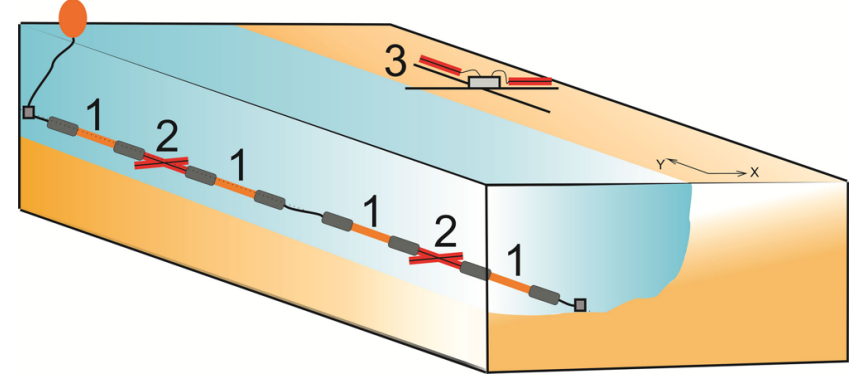

Figure 8. Scheme of the acquisition array implemented in a novel sea floor MT system. Explanation: 1 - receiver dipoles grounded with specialdesign marine electrodes, 2 - two-component magnetometers with high-sensitivity induction coils sensors, 3 - onshore four-component MT layout (reference station).

ment, and is also efficient for the identification of tectonic fault zones. It should be pointed out that most of the area of the Arctic seas falls in this depth range.

The depths ranging from 50 to $200-300 \mathrm{~m}$, apparently require a new special EM technology to be developed, which should use bottom EM stations and/or towed systems, providing field measurements near the sea floor (possibly dragged ones).

For any marine EM studies on the Arctic shelf, the features of the electrical conductivity of the permafrost, discussed above, including lateral macro-anisotropy should be taken into account. Apparently, exciting and receiving the vertical component of the electric field can increase the resolution of EM studies of the subsea permafrost. Since each of the particular EM technologies has both advantages and shortcomings, the most effective solution will be provided by their reasonable targeted integration.

\section{Conclusions}

In the Arctic climatic changes occurring over the past decades have led on the one hand to the acceleration of the subsea permafrost degradation and on the other hand have made it possible to study the structure of the sedimentary formation in the Arctic seas by geophysical methods due to a significant increase in the ice-free area during the summer-autumn season. To date, the information on the distribution and structure of the 
subsea ice-bonded permafrost is fairly limited and fragmented, which makes those studies a very important and urgent task.

The structure of the subsea permafrost is determined by both cryogenic (freezing of the upper layers during regressions) and post-cryogenic (degradation during transgressions) processes and exhibits a significant lateral heterogeneity (taliks, paleochannels, craters, plough marks and so forth).

A significant characteristic for the shelf permafrost is the presence of an uppermost thawed layer with electrical resistivity not exceeding a few $\Omega \mathrm{m}$. Subsea permafrost is generally characterized by lower resistivity, compared to the onshore permafrost, which relates to a thawing and thinlayered (anisotropic) structure, caused by interbedding of the layers with a different electrical conductivity, and also by the possible existence of newly formed ice-bonded permafrost in the seabed sediments.

EM methods are an efficient tool for permafrost imaging both on land and on the Arctic shelf. In the Arctic seas, the study targets are the subsea icebonded permafrost spread over the vast areas with sea depths of up to $100-120 \mathrm{~m}$, and the underlying thawed sedimentary rocks including possible free gas and gas hydrate accumulations. With the help of EM methods (primarily, magnetotellurics), it is possible to study the structure of the crystalline basement and reveal tectonic fault zones. Thus, a new technology of bottom MT sounding allows permafrost and subpermafrost structure imaging in areas with sea depth from 10 to $50 \mathrm{~m}$. The technology allows to cover most parts the Arctic seas, which are free of ice during the summer-autumn season.

Joint application of different EM techniques might be helpful to further enhance the efficiency of EM exploration and its capability of solving a wide range of problems related to subsea permafrost studies, along with the development of new technologies that take into account the features of the electrical conductivity structure on the Arctic shelf.

Acknowledgments. The authors express their deep gratitude to Nord-West Ltd. for providing data from magnetotelluric surveys in Taymyr. The results were obtained in the framework of the state assignment of FASO Russia (Theme No. 0149-2018-0005).

\section{References}

Afanasenkov, A. P., R. P. Volkov, D. V. Yakovlev (2015), Anomalies of high electrical resistivity beneath the permafrost - a new signature of hydrocarbon accumulations, Geology of Oil and Gas, 1, No. 6, 40-53. (in Russian)

Andreassen, K., et al. (2017), Massive blow-out craters formed by hydrate-controlled methane expulsion from the Arctic seafloor, Science, 356, 948953.

Archie, G. E. (1942), The electrical resistivity $\log$ as an aid in determining some eservoir characteristics, Petroleum Transactions of AIME, 146, 54-62.

Baranov, M. A., S. V. Kompaniets, I. V. Buddo, et al. (2014), Capabilities of electromagnetic soundings in the mapping of permafrost, Bulletin of Irkusk State University, 7, No. 90, 25-30. (in Russian)

Barsukov, P. O., $\quad$ E. B. Fainberg (2014), Transient marine electromagnetics in shallow water: A sensitivity and resolution study of the vertical electric field at short ranges, Geophysics, 79, No. 1, E39-E49, Crossref

Barsukov, P. O., $\quad$ E. B. Fainberg (2017), Transient marine electromagnetics in shallow water: A sensitivity and resolution study of the vertical electric field at short ranges, Geophysical Prospecting, 65, No. 3, 840-858, Crossref

Brothers, L. L., et al. (2016), Subsea Ice-Bearing Permafrost on the U.S. Beaufort Margin, Part 1: Minimum Seaward Extent Defined from Multichannel Seismic Reflection Data, Geochemistry, Geophysics, Geosystems, 17, No. 11, 4354-4365, Crossref

Constable, S. (2010), Ten years of marine CSEM for hydrocarbon exploration, Geophysics, 75, No. 5, 75A67-75A81, Crossref

Constable, S. (2013), Review paper: Instrumentation for marine magnetotelluric and controlled source electromagnetic sounding, Geophysical Prospecting, 61, No. Suppl. 1, 505-532, Crossref

Constable, S. C., P. Kannberg, K. A. Weitemeyer (2016), Vulcan: adeep-towed CSEM receiver, Geoch. Geophys. Geosyst., 17, 1042-1064.

Dakhnov, V. N. (1941), Well Logging. Interpretation of Logs, 498 pp. Gostoptekhizdat, Moscow. (in Russian)

Du Frane, W. L., et al. (2015), Electrical properties of methane hydrate + sediment mixtures, J. Geophys. Res. Solid Earth, 120, 4773-4783, Crossref

Epishkin, D. V. (2018), Electrical properties of methane hydrate + sediment mixtures, Development of data processing methods for synchronous magnetotelluric soundings, PhD Thesis, p.133, Moscow State University, Moscow. (in Russian)

Epishkin, D. V., A. G. Yakovlev, D. V. Yakovlev (2018), Technology of marine coastal magnetotelluric sounding, Proceedings of the International geologi- 
cal and geophysical conference "GeoEurasia 2018". Modern methods of studying and exploration of the subsurface resources of Eurasia p.781-784, Polypress, Tver. (in Russian)

Flekkøy, E. G., $\quad$ E. Håland, $\quad$ K. J. Måløy (2012), Comparison of the low-frequency variations of the vertical and horizontal components of the electric background field at the sea bottom, Geophysics, 7r, No. 6, E391-E396, Crossref

Frederick, J. M., B. A. Buffett (2014), Taliks in relict submarine permafrost and methane hydrate deposits: pathways for gas escape under present and future conditions, J. Geophys. Res.: Earth Surf., 119, 106-122, Crossref

Helwig, S. L., et al. (2013), Vertical dipole CSEM: technology advances and results from the Snohvit field, First Break, 31, No. 4, 89-93.

Kiselev, A. A., A. I. Reshetnikov (2013), Methane in the Russian Arctic: Observational results and calculations, Problems of the Arctic and Antarctic, 2, No. 96, 5-15. (in Russian)

Koshurnikov, A. V., et al. (2016), The first ever application of electromagnetic sounding for mapping the submarine permafrost table on the Laptev Sea, Dokl. Earth Sci., 469, 860-863, Crossref

Leibman, M. O., et al. (2017), Chemical features of the lake water and gas discharge sites hosted in marine sediments of the north of Western Siberia, Proceedings of the XXII International Scientific Conference (School) on Marine Geology, Moscow, November 20-24, 2017, Vol. 4 p.118-121, SIO RAS, Moscow. (in Russian)

Lindgren, A., et al. (2016), GIS-based Maps and Area Estimates of Northern Hemisphere Permafrost Extent during the Last Glacial Maximum, Proceedings of the XXII International Scientific Conference (School) on Marine Geology, Moscow, November 2024, 2017, Vol. 4 27, p.6-16, Crossref

Lobkovskiy, L. I., S. L. Nikiforov, N. N. Dmitrevskiy, et al. (2015), Gas extraction and degradation of the submarine permafrost rocks on the Laptev Sea shelf, Oceanology, 55, 283, Crossref

Malakhova, V. V. (2014), Mathematical modeling of the long-term dynamics of the permafrost of the Arctic shelf, Proceedings of the International Scientific Congress "Interexpo Geo-Siberia", Vol. 4, No. 1 p.136-140, SSUGT, Novosibirsk. (in Russian)

Menzies, J., Jaap J. P. Van der Meer, (eds.) (2018), Past Glacial Environments, second edition, $817 \mathrm{pp}$. Elsevier, Amsterdam. Crossref

Montelli, A., J. A. Dowdeswella, D. Ottesenb, S. E. Johansenc (2018), 3D seismic evidence of buried iceberg ploughmarks from the midNorwegian continental margin reveals largely persistent North Atlantic Current through the Quaternary, Marine Geology, 399, 66-83, Crossref

Osterkamp, T. E. (2001), Sub-sea permafrost, Encyclopedia of Ocean Sciences, second edition p.559-569, Elsevier Inc., Amsterdam.

Palshin, N. A. (2009), Problems of marine electro- magnetic soundings, Geophysical Journal, 31, No. 4, 78-92.

Paull, C. K., et al. (2007), Origin of pingo-like features on the Beaufort Sea shelf and their possible relationship to decomposing methane gas hydrates, Geophys. Res. Lett., 34, L01603, Crossref

Portnov, A., A. J. Smith, J. Mienert, et al. (2013), Offshore permafrost decay and massive seabed methane escape in water depths $>20 \mathrm{~m}$ at the South Kara Sea shelf, Geophys. Res. Lett., 40, 1-6, Crossref

Portnov, A., S. Vadakkepuliyambatta, J. Mienert, A. Hubbard (2016), Ice-sheet-driven methane storage and release in the Arctic, Nature Communications, 7, 10314, Crossref

Rachold, V., D. Yu. Bolshiyanov, M. N. Grigoriev, et al. (2007), Near-shore Arctic Subsea Permafrost in Transition, EOS: Transactions of the American Geophys. Union, 88, No. 13, 149-156.

Rekant, P., H. A. Bauch, T. Schwenk, et al. (2015), Evolution of subsea permafrost landscapes in Arctic Siberia since the Late Pleistocene: a synoptic insight from acoustic data of the Laptev Sea, Arktos, 1, 111, Crossref

Romanovskii, N. N., H.-W. Hubberten, A. V. Gavrilov, et al. (2005), Offshore permafrost and gas hydrate stability zone on the shelf of East Siberian Seas, Geo-Marine Letters, 25, No. 2-3, 167-182, Crossref

Schwalenberg, K., D. Rippe, S. Koch, C. Scholl (2017), Marine-controlled source electromagnetic study of methane seeps and gas hydrates at Opouawe Bank, Hikurangi Margin, New Zealand, J. Geohys. Res., 122, No. 5, 3334-3350, Crossref

Sherman, D., P. Kannberg, S. Constable (2017), Surface towed electromagnetic system for mapping of subsea Arctic permafrost, Earth Planet. Sci. Lett., 460, 97-104.

Shakhova, N., I. Semiletov, A. Salyuk, et al. (2010), Extensive Methane Venting to the Atmosphere from Sediments of the East Siberian Arctic Shelf, Science, 327, No. 5970, 1246-1250, Crossref

Shakhova, N., et al. (2017)), Current rates and mechanisms of subsea permafrost degradation in the East Siberian Arctic Shelf, Nature Communications, 8, 15,872, Crossref

Shpolyanskaya, N. A. (2015), Pleistocene-Holocene History of the Permafrost Evolution in Russian Arctic Through the Eyes of Underground Ice, 370 pp. Institute of Computer Research, Moscow-Izhevsk. (in Russian)

Vanyan, L. L., N. A. Palshin (1993), Interpretation of seafloor frequency-domain soundings, Physics of the Solid Earth (Fizika Zemli), No. 12, 65-66. (in Russian)

Waite, W. F., J. C Santamarina, D. D. Cortes, et al. (2009), Physical properties of hydrate-bearing sediments, Rev. Geophys., 47, RG4003, Crossref

Weiss, C. J. (2007), The fallacy of the "shallow-water problem" in marine CSEM, Geophysics, 72, No. 6, A93-A97, Crossref 
Weyl, P. K. (1964), On the change in electrical conductance of seawater with temperature, Limnol. Oceanogr., 9, No. 1, 75-78.

Woodworth-Lynas, C. M. T., H. W. Josenhans, J. V. Barrie (1991), The physical processes of seabed disturbance during iceberg grounding and scouring, Cont. Shelf Res., 11, 939-951.

Yakovlev, D. V., D. V. Epishkin, A. G. Yakovlev, et al. (2017), The structure of permafrost on the Arctic shelf according to magnetotelluric data, Proceedings of the XXII International Scientific Conference (School) on Marine Geology Moscow, November 20-24, 2017, V. 5 p.269-273, SIO RAS, Moscow. (in Russian)

Yakovlev, D. V., O. A. Valyasina, A. G. Yakovlev (2018), Study of the permafrost of the northern surrounding of Siberian platform, based on regionalscale electrical prospecting survey data, Cryosphere of the Earth XXII, No 5 p.76-98, GEO, Novosibirsk. (in Russian)
Yakupov, V. S. (2008), Geophysics of Permafrost, 342 pp. Yakutsk State University Publishing House, Yakutsk. (in Russian)

Yegorov, I. V., N. A. Palshin (2015), Excitation of electrokinetic effects at the shallow bottom by surface waves, Oceanology, 55, No. 3, 417-424, Crossref

Yegorov, I. V., N. A. Palshin (2017), On the origin of background fluctuations in electric field measurements on the seafloor, Izv. Physics of the Solid Earth, 53, No. 3, 446-453, Crossref

N. A. Palshin and E. A. Piskunova, Shirshov Institute of Oceanolgy RAS, Nakhimov Avenue 36, 117997 Moscow, Russia. (Palshin@ocean.ru)

D. V. Yakovlev, Nord-West Ltd, Business Park "Rumyantsevo", Bld 1A, Office 412A, 108811 Moscow, Russia 